ting trekken van verschillende vormen van boschbezit voor het Nederlandsche boschwezen in het algemeen van belang kan zijn.

Dit doel kan bereikt worden hetzij door de verschillende hier aangevoerde vragen ter beslissing aan den fiscalen rechter voor te leggen, hetzij door wijziging van de wettelijke voorschriften. Dit laatste zou kunnen geschieden door de in art. 22 neergelegde vrijstelling nader te omschrijven of door het artikel zoodanig te wijzigen, dat de mogelijkheid wordt geschapen, dat het aan boschbezitters vrijstaat zelf te bepalen welk bosch of gedeelte daarvan niet als boschbedrijf moet worden aangemerkt. Dit zou kunnen geschieden op soortgelijke wijze als thans is voorgeschreven in de Natuurschoonwet 19:28. Een andere mogelijkheid is, dat art. 22 ongewijzigd blijft, doch van Departementswege aan de fiscale ambtenaren een instructie wordt gegeven, behelzende een beperktere opvatting van het begrip ,.boschbedrijf".

$\mathrm{Nu}$ ook het Besluit op de Inkomstenbelasting, in het kader van de vernieuwing van ons belastingstelsel, eveneens op de helling moet komen (zie het artikel van de hand van Dr. Schendstok in het Oriënteeringsnummer I van de Economisch Statistische Berichten), acht ik het tijdstip gunstig hierbij tevens de positie van den boscheigenaar onder de loupe te nemen en de in het algemeen boschbelang noodzakelijke wijzigingen aan te brengen.

\title{
REPERTORIUM VAN LITERATUUR OP HET GEBIED VAN ACCOUNTANCY EN BEDRIJFSHUISHOUDKUNDE
}

Redactie: Centrale Documentatiedienst inzake bedrijfsorganisatie N.V. (C.D.B.)

\section{TIJDSCHRIFTENREPERTORIUM}

\section{A. ACCOUNTANCY}

\section{HET ACCOUNTANTSBEROEP}

\section{The future of the profession}

Redactie - Bespreking van de betrekkingen tusschen de accountants en de zakenwereld in de toekomst. Verwacht mag worden dat deze externe verhoudingen meer ingewikkeld zullen worden, hetgeen toegelicht wordt aan de hand van drie voorbeelden, n.l. t.o.v. de nationalisatiepolitiek, de ingewikkeldheid van de belastingwetgeving en de voorgestelde wijziging van de vennootschapswetgeving. Gevreesd wordt, dat vooral door dit laatste de aandacht van den accountant van zijn eigenlijke taak - het meten van de winsten in verhouding tot de efficiency - afgeleid wordt.

A II 1

The Accountant 16 Maart 1946

\section{LEER VAN DE INRICHTING}

\section{Standardisation of account}

Redactie - Een pleidooi voor het invoeren van uniforme boekhouding en uniforme kostprijsberekening. Ten behoeve van de samenwerking tusschen verschillende personen in het bedrijf en in den bedrijfstak is uniforme kostprijsberekening gewenscht, speciaal ondat binnen afzienbaren tijd weer meer normale concurrentie gevoerd zal worden op de wereldmarkten. Verschillende posten van de in te voeren uniforme balansen en verlies- en winstrekeningen worden besproken. Het is wenschelijk de verslagen van de onderneming meer uniform te maken.
A III 2
The Certified Accountants Journal Maart 1946 


\section{Apprentice record cards}

Harvey, O. L. - Uitvoerige uiteenzetting over de inrichting en het gebruik van registratiekaarten voor het werk van leerlingen in groote bedrijven. Voorbeelden van deze kaarten en van het gebruik ervan. Ook wordt gewezen op de voordeelen, die aan het gebruik van deze .,apprentice record cards" zijn verbonden.

A III 3

Personnel No. 4 Mei 1941

$32-4: 292$

\section{LEER VAN DE CONTROLE}

\section{The costing of government contracts}

Pears. S. J. - Verslag van een lezing over het bepalen van de kosten van regeeringscontracten in oorlogstijd. In het kort worden behandeld: het doel van het onderzoek, soorten onderzoekingen, "post-costing" (het bepalen van de kosten van een contract nadat de productie voltooid is), uitgaven welke de contractant in zijn kostprijs kan berekenen (uitvoeriger), ,costing for information" met het doel om standaardprijzen te bepalen en tenslotte principes welke bij het onderzoek in acht moeten worden genomen.

A IV 1

The Accountant 16 Maart 1946

29.07

\section{B. BEDRIJFSHUISHOUDKUNDE}

\section{a. ALGEMEENE BEDRIJFSHUISHOUDKUNDE}

\section{BEDRIJFSHUISHOUDKUINDE ALS WETENSCHAP}

\section{Bedrijfseconomie en de nieuwe orienteering}

Mey, Dr. A. - Een korte opsomming van de problemen waarvoor de bedrijfseconomie zich in verband met de reconstructie van het productie-apparaat onder leiding van de Overheid gesteld ziet. Ook de organisatie van het bestuursorganisme en de personeelvraagstukken die $^{*}$ zich hierbij voordoen, zullen onderwerp van studie moeten uitmaken.

B a II 1 Maandblad voor Accountancy en Bedrijfshuishoudkunde

$$
\text { No. 1. Jan. } 1946
$$

\section{WAARNEMINGSMIDDELEN}

\section{Het statistisch denken in het industrieele bedrijf}

S ittig. J. - De gedachte zal zich baan moeten breken, dat de massaproductie een statistische mentaliteit van den bedrijfsleider vereischt. In het buitenland is de toepassing statistische methoden in de industrie reeds ver gevorderd. Beschreven worden eenige essentieele trekken van het statistisch denken van den technicus, waarna de resultaten aan de hand van een practisch vraagstuk worden toegelicht.

$$
\text { B a III } 1 \quad \text { Organisatie en Efficiency No. 3. Dec. } 1945
$$

$86: 313.1$

De ontwikkeling der technische statistiek in Engeland gedurende den oorlog

En ters, J. H. - In Engeland heeft "statistiek" als middel tot het analyseeren van gegevens zeer den nadruk gekregen. Schr. geeft een overzicht van methoden welke in vele industrieele bedrijven worden gebruikt, vooral voor kwaliteitscontröle. Proeven en analyses. Geïllustreerd, literatuur.

B a III 2 Tijdschrift voor Efficiency en Documentatie No. 2. 1946

\section{Die dokumentarische Auswertung von Verwaltungsakten}

Rickli, E. - Beknopt artikel over het bewerken van beheersdocumenten voor documentatie-doeleinden. Alleen de belangrijkste beheersdocumenten worden in het documentatiesysteem opgenomen. Gebruik, der Universeele Decimale Classificatie voor het rangschikken naar onderwerp. Opberging per onderwerp in hangmappen. $\mathrm{B}$ a III 2 F.I.D. Communicationes No. 1/2. April 1945

\section{LEER VAN DEN KOSTPRIJS EN DE PRIJSVORMING}

\section{Theoretical conceptions of fixed asset valuation}

B r a y, F. S. - Schr. geeft een korte beschouwing over het verschil in zienswijze tusschen economen en accountants betreffende de waardeering van vast kapitaal. Waar de laatsten waardeeren naar historische kosten eischen de eersten een schatting op grond van toekomstig inkomen dat het vaste kapitaal zal afwerpen. Tenslotten wordt zeer in het kort aangegeven hoe de accountant een correctie d.m.v. de algemeene prijsindex in zijn waardeering kan aanbrengen teneinde aan de wenschen der economen eenigszins tegemoet te komen. 


\section{Afschrijvingen bij de Inkomstenbelasting}

$\mathrm{He}$ a viside, R. - Schr, beoogt weinig meer dan verduidelijking van de economische beginselen bij afschrijvingen op vastgelegd kapitaal, in het bijzonder op het duurzame gebruiksgoed. Met betrekking tot wezen en de grootte der afschrijving gaat hij uit van de afschrijving als factor van de kostprijsberekening bij de financiering en de liquiditeit en bij de balanswaardeering.

B a IV 6 Weekblad der Belastingen No. 3782.16 Maart 1946

Over den zin van prijzen en prijsschommelingen in verband met de bedrijfseconomische leer van de winst

$\mathrm{R}$ a v e s tij n, Dr, H. P. W. - Beknopte bespreking van enkele principieele aspecten van de bedrijfseconomische leer van balanswaardeering en winstbepaling in het kader der algemeen economische waardebepaling. Betoogd wordt, dat de beginselen van de vervangings- en reproductiewaarde, hoewel ongetwijfeld van groote beteekenis, toch slechts een beperkte "gelding" hebben. gebonden aan bepaalde economische veronderstellingen. B a IV 8 De Naamlooze Vennootschap No. 9/10. Febr. 1946

551

lets over goodwill enz.

W intersteij n, M. C. - Korte algemeene behandeling van de vragen, welke zich voordoen bij de berekening van de waarde van den goodwill, bij het overnemen van een zaak in haar geheel, of een deel daarin. Voorbeeld van een berekening.

B a IV 8 Tijdschrift voor Efficiency en Documentatie No. 2. 1946

554.8

\section{LEER VAN DE FINANCIERING}

\section{Kapitaalschaarschte en wederopbouw II}

Koopmans, Prof. Mr. G. J. - Op grond van de door den oorlog ontstane schaarschte-economie werkt schr. de algemeene principes uit, welke moeten gelden bij de toewijzing van investeeringsvergunningen voor wederopbouw. Productiviteit en rentabiliteit als selectiemaatstaven en de functie van den rentevoet bij de beoordeeling hiervan. Schr. concludeert tot een algemeene noodgedwongen verlaging der kapitaalintensiteit. Het probleem is internationaal bezien. Zeer interessant en duidelijk artikel.

B a V 2 Economisch Statistische Berichten No. 1476. 1 Aug. 1945

$134+151$

\section{LEER VAN DE ORGANISATIE}

\section{Vestigingsmogelijkheden van zwaarindustrie in Nederland}

Groothof, A. - Korte bespreking van de vestigingsmogelijkheden van de 2 waarindustrie hier te lande, waarbij behandeld worden: het begrip, toekomstmogelijkheden. vestigingsfactoren en de terreinkeuze.

B a VI 8 Tijdschrift voor Economische Geographie No. 1. 15 Jan. "46

\section{Functie en beteekenis van den importagent}

Faber, N. $H_{n}$ - Korte uiteenzetting van de functie van den importagent in de organisatie van den handel in verband met het probleem of het "direct" koopen van den buitenlandschen producent niet goedkooper is, en daardoor tot uitschakeling van den agent zal leiden.

B a VI 9

Groothandel No. 8. 23 Febr. 1946

711.51:015

De beteekenis van de marktanalyse voor het bedrijf $\mathrm{I}$.

Buys, G. F. - Algemeene beschouwing over de marktanalyse. Achtereenvolgens worden behandeld: begrip en gebied van de marktanalyse, het belang van de marktanalyse voor de bedrijfshuishouding, algemeene begrippen, algemeene hulpmiddelen welke ten dienste van de marktanalyse staan.

B a VI 12 Tijdschrift voor Interne Bedrijfsorganisatie No. 1. Jan, 1946

\section{Martkanalyse voor gemeentebedrijven III}

L o of $f, J . P$. - Bespreking van enkele methodes, die een juist inzicht dienen te geven in de ontwikkeling van de onderneming. Behandeling van eenige methodes ter bepaling van de trendlijn: vrije handmethode, methode der moving averages, methode der kleinste kwadraten. Uitwerking van een, aan de praktijk ontleend voorbeeld. Geïllustreerd.

B a VI 12

Financieel Overheidsbeheer No. 1.15 Jan. 1946

754.5

\section{De toekomst der N.V.}

Grinten, Mr. W. C. L. v. d. - Een tamelijk uitvoerige beschouwing over de N.V. als ondernemingsvorm, waarbij zoowel de voor- als de nadeelen ter sprake komen. In het bijzonder wordt de fiscale positie van de N.V. behandeld, waarbij schr. pleit voor een verschillende fiscale behandeling van publieke en gesloten N.V.'s

B a VI 14 De Naamlooze Vennootschap No, 6/7. Nov./Dec. 1945 


\section{Het probleem der belastingheffing van coöperatieve vereenigingen}

Monod de Froideville, Dr. J. A. - In een beschouwing over het economisch karakter en de economische onderscheiding van de verschillende soorten coöperaties bespreekt schr. de verschillende uitkeeringen die aan leden worden gedaan en de thans gevolgde winstbepaling in het belastingrecht.

B a VI 14

Openbare Financiën No. 1. 1946

$114.7: 551$

\section{Open en besloten naamlooze venuootschappen}

$\mathrm{Sch}$ a a f $\mathrm{sma}, \mathrm{Mr}$. J. R. - Schr. gaat na in hoeverre de onderschelding open tot besloten vennootschap gelijk te stellen is aan die van zelfstandige tot onzelfstandige onderneming. Beide indeelingen komen niet overeen, er heerscht een terminologische verwarring als gevolg van vaagheid in de begripsbepaling.

B a VI 14 De Naamlooze Vennootschap No. 8. Jan. 1946

114.44

De waarde van enkele critiekpunten op het stelsel van de variabele budgetteering

$\mathrm{K}$ i e n, P. Ch. J. - Als voorbereiding tot een onderzoek naar de steekhoudendheid van een tweetal belangrijke critiekpunten op het systeem van de variabele budgetteering wordt een summiere uiteenzetting van dit systeenı gegeven. Hierna gaat schr. op deze punten in, n.l. op de vraag of het noodzakelijk is, dat het budget in de boekhouding opgenomen wordt en op het feit, dat slechts een klein gedeelte der indirecte kosten proportioneel met de bezetting fluctueert.

B a VI 18 Tijdschrift voor Interne Bedrijtsorganisatie

No. 1. Jan. 1946 en No. 2. Febr. 1946

298.2

Organisatie van de mechanische werkplaatsen voor onderhoud en reparatie in groote bedrijven

Ditzhuyzen, Ing. H. v. - Schr. geeft normen voor werkplaatsen, welke tot primaire taak hebben het onderhoud te verzorgen van het productieapparaat in een groot bedrijf. Beschrijving van de drieledige taak van deze werkplaatsen. B a VI 19

Tijdschrift voor Interne Bedrijfsorganisatie No. 2. Febr. 1946

\section{Fabrieksbouw en bedrijfsorganisatie}

K ooy, C. - Bespreking van eenige factoren, welke van invloed zijn op den bouw en de inrichting van een fabriek. Behandeld worden: de verlichting, de luchtbehandeling (uitvoeriger) en eenige bedrijfstechnische eischen.

B a VI 19 Tijdschrift voor Interne Bcdrijfsorganisatie

No. 2. Febr. 1946

\section{LEER VAN DE ARBEIDSVOORWAARDEN}

\section{Monetary incentive methods}

Vernon Bosly, J. - Bespreking van stimulansen bij den arbeid. Stimuleerende loonstelsels zijn gemakkelijker te classificeeren dan productie-omstandigheden. Het toekennen van individueele premies, premies voor ",shops", het groepbonussysteem, schema's voor individueele bonustoeslagen. De voor- en nadeelen van deze systemen worden in het kort besproken.

B a VII 3

Industry Illustrated No. 1. Jan. 1946

373,6

\section{Enkele beschouwingen over loonstelsels}

Gogh, Ir. V. W. v. - Behandeling van de technische zijde van deze vraagstukken. Voordeelen van het stukloon; ingewikkelder stelsels, reden voor premiebetaling; bespreking van verschillende stelsels; oorzaken voor de vele toepassingen ofschoon het begrip "Ioon naar prestatie" verlaten is. Geillustreerd.

$\mathrm{B}$ a VII 3 Organisatie en Efficiency No. 1/2. Jan./Febr. 1946

\section{Labor relations of 1941 ; cooperation vs dictation}

Hersey, R. B. - Interessante verhandeling over de principes welke ten grondslag liggen aan een goede verstandhouding tusschen werknemers en -gevers. Geanalyseerd worden verhoudingen in de fabriek welke door de leiding nagestreefd moeten worden. Hierbij komt nog de individueele behandeling van den arbeider. Getuigend van groote practische en theoretische kennis.

$\mathrm{B}$ a VII 4

Personnel No. 4. Mei 1941

\section{Werkelijke bedrijfsgemeenschap}

Verwoerd. W. - Algemeene beschouwing over de gedachte van de vorming van een werkelijke bedrijfsgemeenschap. Schr. bespreekt de noodzakelijke wijziging die in de sociale structuur van het bedrijfsleven zal moeten geschieden, daar werkgevers en 
-nemers in twee kampen tegenover elkaar staan. In verband hiermede behandelt hij den ondernemingsraad.

B a VII 4

Tijdschrift voor Interne Bedrijfsorganisatie No. 1. Jan. ${ }^{* 46}$

The selection and training of inspectors

$\mathrm{T}$ if $\mathrm{f} \mathrm{in}, \mathrm{J}$. and $\mathrm{R}$ ogers, H. B. - Interessant artikel waarin vnl. de methoden en tests beschreven worden, welke gebruikt worden bij het selecteeren van kwaliteitscontroleurs.

B a VII 5

Personnel No. 1. Juli 1944

$395: 636$

\section{The induction of new factory employees}

Y e o m a ns, G. E. - Behandeling van de beteekenis van de inleiding van nieuwelingen in het bedrijf. De eerste indruk, het verwelkomen, handboeken, het introduceeren. een programma hiervoor.

$\mathrm{B}$ a VII 7

Personnel No. 1. Juli 1942

361.7

Planning industrial recreation

Dug g in s, G. H. and F. R. E a st wood - Aan de hand van een studie van ontspanningsprogramma's van bedrijven hebben schr. een modelprogramma opgesteld. $Z_{i j}$ beschrijuen de organisatie, het opstellen van de werkzaambeden en de financiering van het programma.

B a VII 8

Personnel No. 1. Juli 1942

385.5

Make the plant a good place to work.

$\mathrm{R}$ ing, W. A. - Beschrijving (met foto-illustratie) van de instellingen en maatregelen van de Governor $\mathrm{Cy}$. teneinde voor het personeel een aangename materieele en sociale werkomgeving te scheppen. Inrichting, verlichting, ventilatie, muziek, cafetaria, kleed- en badkamers, theaterzaal, loonpolitiek, werkkleeding, ontspanning, gezondheidszorg enz.

B a VII 8

Factory Management and Maintenance No. 8. Aug. 1945

385

\section{b. BIJZONDERE BEDRIJVEN}

\section{INDUSTRIE}

Die Dokumentation der Aluminiumwerke Neuhausen A.G.

Kocherhans. E. - Interessant artikel over de werkzaamheden van de documentatie-afdeeling eener aluminiumfabriek. Gebruik der Universeele Decimale Classificatie voor het ordenen der documenten volgens onderwerp. Alfabetische kaartsystemen als neveningangen voor de aluminiumlegeeringen en de diverse firma-catalogi. Wekelijksch bericht der documentatieafdeeling met boek- en tijdschriftbesprekingen. Regeling van de circulatie der tijdschriften door het bedrijf, na lezing terugzending aan de documentatie afdeeling die voor doorzending naar de volgende afdeeling zorg draagt.

$\mathrm{B}$ b V 4 F.I.D. Communicationes No. 3/4. Sept. 1945

B433:926

\section{TRANSPORT EN ANDERE DIENSTVERLEENING.}

\section{L.M.S. Railway clerical methods - goods train traffic}

Vine, W. H. - Beschrijving van de administratieve werkzaamheden voor het goederenvervoer van de L.M.S. Bespreking van de vrachtbrieven, verwerking hiervan in de administratie, tarieven, verzending van de goederen.

B b VII 2

Industry Illustrated. No. 11. Nov. 1945

B612

\section{FINANCIERINGSINSTELLINGEN}

\section{La documentation d'une grande banque commerciale}

Viret, C. L. - Summiere bespreking van de werkzaamheden van de documentatieafdeeling van een bank. De verschillende documentatiebronnen. Opberging van de verschillende documenten, dossierstelsel. Oppervlakkige behandeling van het gevolgde registratuurplan.

$\mathrm{B}$ b $\times 2$

F.I.D. Communicationes No. 1/2. April 1945

B72:926

\section{Geschiedenis en ontwikkeling van het gemeentelijk bankwezen II.}

L o of $f, J$. P. de - Schets van de sociale en economische aspecten van het spaarwezen. Besproken worden: het sparen, het beleggen, principes, die hierop van toepassing zijn, soliditeit, rentabiliteit, liquiditeit.

$\mathrm{B}$ b $\times 7$

Financieel Overheidsbeheer No, 1, 15 Jan. 1946

$\mathrm{m} \mathrm{a} \mathrm{b}$ blz. 116 